\title{
MOTIVOS DA RECUSA À DOAÇÃO DE ÓRGÃOS APONTADOS POR FAMILIARES DE PESSOAS COM MORTE ENCEFÁLICA
}

\section{Reasons for refusing to donate organs reported by relatives of individuals with brain death}

\author{
Jana Aparecida Paccielli Camatta1, Heloisa Wey Berti², Jairo Aparecido Ayres², Vera Lúcia Pamplona Tonete²
}

\section{RESUMO}

Objetivo: Apreender os motivos da recusa à doação de órgãos, a partir de familiares de potenciais doadores, residentes na região centrooeste do estado de São Paulo. Método: Estudo qualitativo, realizado após levantamento de dados junto ao setor de Organização de Procura de Órgãos (OPO), localizado em um hospital de referência da região. Os familiares foram contatados para realização de entrevista semiestruturada, na qual, após caracterização dos sujeitos do estudo, foram apresentadas quatro questões norteadoras, tendo sido as respostas gravadas e posteriormente transcritas. Para a organização dos discursos dos entrevistados, empregou-se o método de Análise de Conteúdo, proposto por Bardin. Resultados: No período de 2006 a 2008, 30 (35,3\%) das famílias contatadas pela OPO recusaram-se a dar seu consentimento à doação dos órgãos. Desse universo, foram entrevistados membros de 16 famílias. Os dados foram sistematizados em três grandes temas: a experiência de ser informado da morte encefálica do familiar, decisão sobre a solicitação da doação de órgãos e aspectos que facilitariam a decisão de concordar com a doação de órgãos. Conclusão: A identificação dos motivos da recusa e as sugestões apresentadas fornecem subsídios para melhoria do processo de doação de órgãos para transplantes.

Descritores: Morte Encefálica; Transplante de Órgãos; Família; Bioética.

\section{Instituição:}

${ }^{1}$ Curso de Graduação em Enfermagem da Faculdade de Medicina de Botucatu - UNESP.

${ }^{2}$ Departamento de Enfermagem da Faculdade de Medicina de Botucatu - UNESP.

\section{Correspondência:}

Jana Aparecida Paccielli Camatta

Rua Francisco Casini, 330, Botucatu - CEP 18603-250 - São Paulo/ SP - Brasil.

Fone: (14) 9748-4642

E-mail: janacamatta@hotmail.com

\section{INTRODUÇÃO}

Doação e transplante de órgãos é assunto de grande importância na área da saúde e vem ganhando espaço em discussões, tanto intrahospitalares quanto em meio à comunidade em geral. Porém, muita dúvida e receio sobre "o que é doação", "como é feito o transplante", "quem pode doar", "o que é morte encefálica" e outras questões envolvidas nesse assunto, estão presentes nos referidos meios. Inclusive, os profissionais da saúde como médicos, enfermeiros, técnicos e auxiliares de enfermagem, muitas vezes, não sabem como agir frente a um caso de doação e transplante de órgãos.1 Sendo assim, é importante esclarecer questões relacionadas ao que é doação e o que é transplante de órgão.

O transplante é um tratamento que visa substituir um órgão que já não está funcionando normalmente, de modo que um tratamento convencional não seria suficiente. Esse órgão substituto pode ser doado pela família de um doador falecido ou por um doador ainda em vida que, se maior de idade, não precisa da autorização famíliar. ${ }^{1}$

Mesmo possuindo um dos maiores programas públicos de transplantes do mundo e com crescimento progressivo, o Brasil ainda tem, registradas na fila de espera por um órgão, mais de sessenta mil pessoas. No país, o primeiro órgão transplantado com doador falecido foi um rim, em 1964, no Hospital dos Servidores do Estado do Rio de Janeiro. $^{2}$ 
Embora sejam feitos aprimoramentos tecnológicos para várias modalidades de transplantes, fatores socioculturais, éticos e legais, muitas vezes dificultam e/ou retardam o avanço desse tipo de tratamento. Segundo pesquisa realizada em 2008, a taxa brasileira de recusa familiar atingiu $22 \%$, ultrapassando a média de recusas aceita internacionalmente. ${ }^{2}$

Um dos maiores empecilhos à doação é a demora na notificação da morte encefálica, sendo esse problema responsável pela perda de metade dos principais doadores. ${ }^{3,4}$ Outra questão muito séria diz respeito ao preparo da equipe que entrevistará a família. Segundo alguns estudos, os familiares tendem a consentir com a doação quando bem orientados. Porém, muitas vezes, a equipe não sabe como falar com a família e isso, além de gerar a recusa, pode causar outros transtornos. ${ }^{4,5}$

É necessário, também, que a equipe conheça e respeite a religiosidade do doador e de sua família, pois esse ainda é um dos motivos de recusa. No Chile, por exemplo, motivos religiosos são causas para recusa familiar na doação de órgãos em $10 \%$ dos casos. ${ }^{6}$

$\mathrm{O}$ treinamento do entrevistador e as atitudes da equipe são fatores fundamentais para o aumento do número de doações, pois para muitas famílias, o processo de doação é desgastante e sofrido.? Estudo feito na Nova Zelândia mostrou que 38 dos 49 entrevistados encontraram grande ajuda no carinho e na compreensão da equipe, ${ }^{8}$ que precisa saber escolher corretamente as circunstâncias em que as conversas com a família devem ser realizadas. Deixar que os familiares exponham os sentimentos e as dúvidas que surgem com a perda de um ente querido faz muita diferença. ${ }^{9}$

Para maior resolubilidade dos problemas e para que o processo de captação, doação e transplante de órgãos seja feito cada vez com mais eficácia, foram criadas no Brasil as Centrais de Notificação, Captação e Distribuição de Órgãos (CNCDO's) e as Organizações de Procura de Órgãos (OPO's). No final da década de 2010 as CNCDO'S totalizavam vinte e quatro em todo o país e, especificamente, no estado de São Paulo as Organizações de Procura de Órgãos totalizavam dez. ${ }^{10}$

Uma delas é a OPO Botucatu, situada no Hospital das Clínicas da Faculdade de Medicina de Botucatu da Universidade Estadual Paulista (HC - FMB- UNESP). Tal organização é formada por uma equipe de onze profissionais, atende a aproximadamente um milhão e duzentos mil habitantes da região centro-oeste do estado de São Paulo, cobrindo cinquenta municípios. Suas atividades baseiam-se no princípio da liberdade de escolha e na gratuidade da doação, o que garante às famílias dos doadores a condição de tomar uma decisão livre de coações. ${ }^{11}$

Os trabalhos da equipe vão desde a busca ativa para identificação do potencial doador, até a doação efetiva. Além disso, a OPO realiza atividades educativas junto à população, através dos meios de comunicação, sobre doação e transplante de órgãos e tecidos, e também conscientiza os jovens quanto aos cuidados com a própria saúde, para que no futuro não venham a precisar de um transplante, devido ao uso de drogas (tabaco, álcool, cocaína, etc.). ${ }^{11}$

Com a estrutura que o Brasil possui através das CNCDO's e das OPO's, o processo de captação, doação e transplante de órgãos deveria ser eficiente, porém ainda hoje há uma quantidade enorme de pessoas na fila por um transplante e a taxa de recusa familiar continua alta, chegando a $70 \%$ nas regiões menos desenvolvidas do país. ${ }^{12}$

A questão central que esta investigação pretendeu responder foi:
"Quais os motivos que levam os familiares de pessoas com ME a recusarem a doação de órgãos?" Deste modo, esse estudo tem por finalidade contribuir para melhor compreensão das perspectivas das famílias em situação de perda de um de seus membros e diante da decisão de doar seus órgãos, com o intuito principal de possibilitar a adoção de medidas mais adequadas, visando a aceitação consciente das famílias ao ato de doar órgãos.

Diante do exposto, objetivou-se apreender os motivos de recusa à doação de órgãos, a partir de familiares de potenciais doadores com morte encefálica, residentes na região centro-oeste do estado de São Paulo, verificar o número de recusas à doação de órgãos nos anos de 2006, 2007 e 2008, identificar, com relação ao potencial doador, procedência, causa da morte, sexo, idade, escolaridade e religião e, quanto aos familiares entrevistados, grau de parentesco com o potencial doador, religião, escolaridade, município de residência, ocupação e descrição da experiência de ser informado da morte encefálica do familiar, bem como sobre a solicitação da doação de órgãos do mesmo.

\section{MÉTODO}

Estudo qualitativo, desenvolvido após levantamento de dados referentes às entrevistas feitas pela OPO do HC - FMB - UNESP, com familiares de potenciais doadores de órgãos, nos anos de 2006, 2007 e 2008, identificando-se as famílias residentes na região centro-oeste do estado de São Paulo que não atenderam à solicitação da referida OPO.

Após identificação dos dados e endereço das famílias, essas foram contatadas pelos pesquisadores para visita domiciliar e entrevista, respeitando-se um período de luto maior que um ano.

As visitas foram realizadas conjuntamente pelos pesquisadores, que solicitaram prévia permissão da família para a visita e para a entrevista. Foram entrevistados os familiares que estavam presentes no momento da solicitação da doação de órgãos e que participaram da recusa a esse pedido.

As entrevistas semi-estruturadas foram feitas mediante apresentação de questões objetivas para caracterização dos sujeitos e de outras quatro questões norteadoras:

1- Poderia nos contar como foi para você e sua família vivenciar a experiência do falecimento do seu familiar?

2- Como foi para você receber o pedido de doação de órgãos de seu familiar?

3- Seria possível apontar quais foram os principais motivos para a recusa de vocês em fazer a doação de órgãos?

4- Você teria alguma sugestão a apresentar para que a doação de órgãos para transplantes fosse mais bem resolvida?

As respostas às questões foram gravadas, transcritas e o referencial de análise foi o de Análise de Conteúdo proposto por Bardin, na vertente temática. ${ }^{13}$

Após leitura exaustiva dos discursos contidos nas entrevistas, foram feitos os recortes das unidades de registro que respondiam aos objetivos deste estudo, as quais foram agrupadas em núcleos de sentido ou categorias, segundo critério semântico das palavras, visando o significado real das unidades de registro. 
Foi atribuída a letra E com o número correspondente à ordem em que as entrevistas foram realizadas, como código de identificação dos entrevistados.

O projeto de pesquisa foi encaminhado ao Comitê de Ética em Pesquisa da Faculdade de Medicina de Botucatu - UNESP, atendendo à Resolução CNS - 196/96, tendo sido aprovado no dia 9 de novembro de 2009 (Of. 418/2009). Após esclarecimentos sobre a pesquisa, os familiares que aceitaram participar do estudo assinaram o Termo de Consentimento Livre e Esclarecido.

\section{RESULTADOS}

Após exame dos registros da OPO do HC - FMB - UNESP sobre entrevistas realizadas com a finalidade de doação de órgãos nos anos de 2006, 2007 e 2008 verificou-se que foram entrevistadas 85 pessoas para a solicitação de doação de órgãos. Destas, 30 (35,3\%) recusaram-se a dar o consentimento, sendo: em 2006, das 26 entrevistas para doação de órgãos houve sete $(26,9 \%)$ recusas; em 2007 das 29 entrevistas houve 11 (37,9\%) recusas e em 2008 das 30 entrevistas houve $12(40,0 \%)$ recusas. Sem informações sobre doação ou recusa, somaram $42(49,4 \%)$ casos. O elevado número de casos sem informação decorre de falhas identificadas nos registros daquela OPO.

As famílias procuradas para participar desta pesquisa totalizaram 28, porque duas delas residiam fora da região centro-oeste do estado de São Paulo. Dessas, oito não foram encontradas (residentes em: Mineiros do Tietê, Itaí, Lençóis Paulista, Laranjal Paulista, Avaré, Sarutaiá e dois residentes em Pederneiras) porque mudaram-se para endereço ignorado, segundo informações dos vizinhos. Quatro familiares recusaram-se a participar, após serem contatados em suas residências nos seguintes municípios: Botucatu (duas famílias), São Manuel e Bauru. Os motivos apontados à recusa ao consentimento para participar desta pesquisa relacionaram-se a sentimentos de revolta com a morte e com o atendimento hospitalar recebido, além do desejo de não tocar mais nesse assunto.

\section{Caracterização dos participantes da pesquisa}

$\mathrm{O}$ total de familiares que aceitou participar desta pesquisa foi 16. Desses, 10 eram do sexo feminino, a maior parte era cônjuge dos potenciais doadores, com ocupação em serviços domésticos, de religião católica. Seis eram procedentes de Botucatu e 10 de outras cidades da região. Quanto à escolaridade dos entrevistados, é interessante registrar que nenhum tinha mais de oito anos de estudo, a maioria tinha menos de quatro anos de estudo, sendo a média de quatro anos, com desvio padrão de 2,3.

Os potenciais doadores, ao morrer, tinham idade variando de 12 a 81 anos, a maioria era do sexo feminino e de religião católica. Apenas três tinham mais de oito anos de estudo e as mortes foram decorrentes de causas externas, tumores, acidente vascular encefálico e eclampsia.

\section{DISCUSSÃO}

\section{Motivos de recusa de doação de órgãos por familiares de potencial doador}

A seguir, serão apresentados os temas, as categorias e inferência ou interpretação dos conteúdos obtidos com as entrevistas junto aos familiares.

\section{Tema 1 - Experiência de ser informado da morte encefálica do familiar}

Nesse tema houve destaque às dificuldades para aceitar a morte do familiar, especialmente por se tratar de morte não esperada, de pessoas supostamente saudáveis e, em alguns casos, decorrente de causas externas. Esse tema foi composto pelos seguintes núcleos de sentido: É muito triste perder alguém, assim, de repente. Não é fácil aceitar a morte de quem é jovem.

Embora a morte seja inerente à vida, na maioria das vezes não se está pronto para enfrentar o impacto causado pela perda de um ente querido e os consequentes desarranjos que essas perdas trazem para o seio familiar, conforme ilustram os depoimentos, a seguir:

[...] era aniversário de um amigo dele, foram comemorar na represa, ao voltar, aconteceu o acidente. $O$ motorista tinha bebido bastante e aconteceu isso. É muita revolta [...]E11. [...] veja bem, ela com saúde, nenhuma doença. Nós com projetos de viagens, de visitar os parentes que moram fora da cidade [...] E16.

$\mathrm{O}$ sofrimento acompanha a perda de um ente querido e a morte repentina é a que provoca intenso choque e abalo aos familiares. As maiores manifestações de tristeza são atribuídas a esse tipo de morte. $^{5}$

Os entrevistados demonstraram sentimentos de tristeza e dor, ligados diretamente ao fato de perderem alguém por morte súbita:

[...] a moto bateu nele. Ele não esperava... Então, ele caiu e quebrou em três partes a cabeça... Foi muito duro, muito triste [...] E12. [...] a experiência foi triste e lamentável. Uma hora, sem esperar, esse baque, essa morte. Pedi a Deus, mas continuo com a dor [...] E16.

Alguns fatores podem dificultar ainda mais esse enfrentamento, como por exemplo, o tipo de morte, a posição e função ocupadas pelo falecido na família, histórias de mortes anteriores, a fase da vida que se interrompeu, dentre outros. ${ }^{14}$

\section{Não é fácil aceitar a morte de quem é jovem. E11}

Pelo ciclo natural da vida, espera-se que o próximo a falecer seja a pessoa mais velha da família. Essa ideia, de certo modo, prepara as pessoas para aceitar a perda com menos dificuldade, embora, com frequência, seja muito difícil.

Mesmo assim, há tempo para que o processo de luto inicie-se antes da perda. Pode-se, então, despedir-se aos poucos, dizer e fazer coisas que gostaria e permitir que a pessoa à morte vivencie esse processo junto com sua família, tendo liberdade de expressar seus sentimentos. ${ }^{15}$

Ao serem quebradas as "leis naturais da vida", esse processo de luto torna-se muito penoso. Quando morre um jovem da família, invertendo assim o ciclo vital, os sentimentos pela perda podem ser muito mais dolorosos, especialmente para os pais:

[...] Ah, foi duro... Muito duro. Você vê uma menina, menina novinha, com vinte anos, menina boa, educada, todo mundo gostava dela na rua. Ela estava lavando roupa e o namorado pegou o revolver e atirou nela. Como eu sofri... A gente não esquece [...]

E4. [...] pra mim, perder assim uma menina, foi um momento de muita tristeza, porque a gente não esperava, foi uma coisa muito rápida. Ela tinha muita dor de cabeça. Ela tava com câncer. A mãe tomou muito calmante pra se controlar [...] E13. 
Além da ruptura no meio familiar, consequente a uma perda "precoce", na maioria das vezes a morte de um jovem ocorre de forma repentina e trágica, tornando esse o pior dos lutos. ${ }^{14,16}$

\section{Tema 2- Decisão sobre a solicitação de doação de órgãos}

Paralelamente a todo o sofrimento relacionado à perda, receber o diagnóstico de morte encefálica pode gerar muita insegurança e dúvida aos familiares para se tomar qualquer decisão. Por ser este um tema mal compreendido e até mesmo desconhecido por muitas pessoas, essa experiência torna-se ainda mais estressante e dolorosa.

Um estudo realizado nos Estados Unidos com 403 famílias entrevistadas sobre a compreensão de morte encefálica mostrou que $21,1 \%$ dessas famílias tinham esperança de melhora do quadro clínico de seu ente. ${ }^{17}$

É nesse contexto de desarranjos pessoais e familiares, onde muitas vezes há dificuldade para compreender e aceitar informações transmitidas pela equipe de saúde, que a OPO assume papel fundamental no processo de captação-doação-transplante de órgãos, enviando um de seus profissionais para entrevistar a família, solicitando o consentimento à doação. ${ }^{18}$

A entrevista familiar é uma etapa de alta complexidade. Em muitos casos, esse é o momento em que a família percebe que realmente não há mais nada a fazer para salvar a vida de seu ente querido, e que as esperanças que tinha, mesmo após o médico tê-la informado sobre a morte encefálica, agora dão lugar ao luto. ${ }^{19}$

Ao serem abordados sobre o momento da solicitação da doação de órgãos de seu ente recém-falecido, os familiares revelaram sentimentos, dúvidas e opiniões que puderam ser sistematizados nos seguintes núcleos de sentido: Naquela hora, não queria ficar esperando ainda mais; Não fui bem orientado sobre a doação; Recusei, pois desconhecia o desejo dele; Fiquei desconfiado do serviço que iriam fazer. Nesse tema, portanto, houve destaque para os motivos que levaram os familiares a não concordar com a doação dos órgãos do parente com morte encefálica.

Naquela hora, não queria ficar esperando ainda mais. E6

A família tende a reagir e a expressar seus sentimentos frente à perda exatamente nesse momento. Em meio ao desespero e confusão emocional, ela precisa tomar uma decisão importante sobre o desfecho dessa história. ${ }^{20}$

A demora no processo de retirada dos órgãos e liberação do corpo é um fator relevante nos casos de recusa. A família, que vive um momento de grande estresse emocional, ao ser informada sobre a necessidade do corpo de seu ente querido permanecer por mais tempo no hospital, para que as equipes de transplante possam retirar os órgãos, tenderá a ser desfavorável à doação:

[...] eu que decidi, mas não liberei... Disseram que demorava bastante, ia pra uma cidade lá. Acho que mais quatro horas. Ai eu assustei, já era mais de meia-noite. Tinha dado a notícia pra familia que ela já tinha falecido e ficar demorando mais ainda... Pelo menos eu queria fazer um velório [...] E14.

O tempo que as famílias têm para decidir, na maioria das vezes, não é suficiente para poder elaborar sua nova realidade e, com o intuito de colocar um ponto final nesse difícil momento, as famílias tendem a recusar a doação:

[...] por mim, eu doaria... Eu ia doar. Só que disseram que ela tinha que ficar mais uns três dias do jeito que ela estava, que tinha que ir pra não sei onde, que tinha que fazer não sei o quê, que iam tirar aos poucos, não iam tirar tudo num dia. Ai eu falei: para com isso! Deixa ela descansar em paz. A intenção era doar, lógico, tudo se pudesse doar. Mas iam ver o que estava bom e o que não estava bom. Falei: minha mulher não é mercadoria, então para de uma vez, desliga o aparelho aí, e acabou a história [...] E3

Além disso, alguns familiares, por não terem compreendido suficientemente o processo de retirada de órgãos, acreditam que não só eles, mas também seu ente querido iria sofrer ainda mais com essa demora:

[...] a mãe dele falou: ele já tá sofrendo, ficou muitos dias na UTI, agora sofrer mais ainda? Então ela falou: não quero que meu filho fique sofrendo mais [...] E12.

Evitar as incertezas relacionadas a esse processo é uma maneira que a equipe de saúde pode agir para que os familiares se sintam um pouco mais seguros e minimizando o sofrimento de todos.

\section{Não fui bem orientado sobre a doação. E1}

É sabido que a entrevista familiar tem de ser realizada por profissional capacitado. Diversos estudos relacionam o preparo desse profissional com o consentimento da família em doar os órgãos. ${ }^{18,19}$ Os entrevistados apontaram atitudes dos profissionais que influenciaram negativamente na decisão de doação:

[...] eles perguntaram pra ele se ele doava os órgãos. Ele ficou muito nervoso naquela hora e não conseguiu responder. Ele achou que era pra doar os órgãos dele pra salvar a vida dela. Daí foi isso aí, ele ficou muito nervoso na hora e falou que não ia doar os órgãos [...] E15.

[...] bom, nós conversávamos antes, sobre doação de órgãos. Ela sempre falava pra mim que queria doar, eu mesmo também falava, mas... Veja bem, a falha foi minha, mas você ver uma pessoa com a caixinha de isopor lá, vindo tirar o órgão... Deveriam chamar a gente sem a caixinha de isopor de lado. Conversar, pra depois a gente dar a resposta. Então, naquele baque, vendo a pessoa com a caixinha de isopor pra tirar o órgão, a resposta foi não [...] E16

Uma explicação detalhada e esclarecedora pode evitar incompreensões que geram angústias ainda mais intensas nos familiares, especialmente considerando os sentimentos decorrentes da morte inesperada de um familiar e suas dificuldades para refletir, em curto espaço de tempo, sobre a possibilidade da doação de órgãos do ente falecido.

Compreender plenamente essa situação é imprescindível por parte de todos os envolvidos no processo de captação-doação-transplante de órgãos.

\section{Recusei, pois desconhecia o desejo dele. E2}

Desde 23 de março de 2001, quando entrou em vigor a Lei 10211, alterando dispositivos da Lei 9434, de 1997, determinouse o consentimento informado como único meio para doação de órgãos. ${ }^{21}$ Dessa forma, a anuência familiar é condição para a efetivação da doação.

Um dos motivos apontados pelos familiares para recusar a doação de órgãos foi o fato de o ente falecido não ter manifestado em vida seu desejo de doar órgãos. Assim, no momento da decisão familiar, quando isso ocorre, há um receio muito grande de permitir a doação e arrepender-se depois, por ter tomado uma decisão possivelmente contrária ao desejo de seu ente querido: 
[...] foi esse dai o motivo, a gente não ter conversado com ele antes. Então, a gente ficou em dúvida, pensando: ai meu Deus! Se a gente vai doar os órgãos, depois a gente fica com remorso... Daí nós não aceitamos [...] E2. [...] é que ele nunca comentou se um dia ia doar ou não. Então, a gente ficou meio assim, mas se ele tivesse falado antes, conversado [...] E11.

A sociedade recebe, através de alguns meios de comunicação, informações relacionadas à importância de avisar a família sobre o desejo de doar ou não os órgãos. Porém, um estudo recente realizado no Brasil mostrou que, de 69 pessoas não favoráveis à doação, 5,8\% têm medo de doar. Esse mesmo estudo mostrou que $20,3 \%$ das pessoas não favoráveis à doação não confiam nos sistemas médicos e de transplante. ${ }^{22} \mathrm{O}$ núcleo de sentido seguinte se refere a essa situação.

Fiquei desconfiado do serviço que iriam fazer.

Constata-se, pelos depoimentos abaixo, que a percepção dos familiares sobre a falta de assistência hospitalar adequada ao paciente, prejudicando o acolhimento concedido a ele e a sua família é outro ponto relevante e presente na recusa para a doação:

[...] eles (demais parentes) achavam que ela não estava morta de verdade e acharam que iria matar ela pra tirar os órgãos [...] E9. [...] a gente sendo doador pode acontecer um acidente e, sei lá... Talvez, disserem: ah, já é doadora, então vamos... Eu sempre pensei nisso. Então, eu não gostava dessas coisas, porque aí você está lá, não está nem morta ainda, já vão tirar, pra arrumar a vida de outra pessoa [...]

E12. [...] ele ficou no corredor, ficou sujo, com sangue pingando. Meu sogro acha que ele morreu porque não foi bem atendido. Porque demorou uma semana pra ele ir pra cirurgia. Acho que ele foi pra cirurgia pra eles estudarem... E ele falava: me tira daqui, eu quero viver, eu não quero ficar aqui. Por isso que a minha sogra não aceitou doar. E, se tivessem cuidado melhor do meu marido e mesmo assim ele tivesse morrido, poderia concordar com a doação [...] E12. [...] se a pessoa for bem tratada no hospital, acho que ajuda na decisão [...] E7.

Outro fator diretamente relacionado à problemática das recusas à doação refere-se às condições estruturais de captação de órgãos, motivo de recusa apontado por alguns dos familiares:

[...] sei lá, um negócio mais assim: Oh, tem um olho, ou um não sei o quê para doar, "Ah, é ali." Coisa assim, no local. Eu acho que está faltando, estruturar melhor. [...] E3

A variedade de motivos das recusas demonstra a necessidade de se dispensar um olhar mais atento em cada situação que se apresenta como entrave à doação de órgãos. Perceber questões-chave dessa problemática é fundamental para elaborar medidas de intervenção que realmente contribuam para o alcance de melhores resultados.

Tema 3 - Aspectos que facilitariam a decisão de concordar com a doação de órgãos

Os familiares entrevistados, ao discorrer sobre possibilidades futuras da anuência em relação à doação de órgãos apontaram alguns aspectos que facilitariam a obtenção do consentimento nesse sentido. Os depoimentos relativos a esse tema foram agrupados nos seguintes núcleos de sentido: Quem sente necessidade de um órgão concorda com a doação. O pedido de doação precisa ser bem explicado. São necessárias ações de esclarecimento da população, devendo ser respeitado o direito de decidir de cada pessoa.

É interessante verificar, neste tema, que pessoas que se negaram a doar órgãos passam, em outro momento, a expressar sentimentos de solidariedade, compaixão e reconhecimento à necessidade do outro em receber um órgão por doação. Pareceram demonstrar algum desconforto por não terem consentido com a doação, especialmente aqueles que, posteriormente, aguardavam a doação de um órgão para si:

[...] a minha família concorda porque a gente precisa. Eu também estou precisando, estou com problema de rim. Um eu perdi, estou fazendo hemodiálise. Então, a gente quer pra gente, a gente também deseja para os outros. Eu acho assim [...] E4.

$O$ pedido de doação precisa ser bem explicado.

Entretanto, como já foi anteriormente discutido, quando solicitado a concordar com a doação de órgãos de seu ente falecido, envolvido por emoções, crenças e valores que afetam decisões, o familiar ressalta a necessidade de explicação detalhada, dando a entender que essa foi a razão para não ter consentido com a doação, apontando também a importância de mais esclarecimentos para a população:

[...] eu acho que tem que ser bem explicado, direitinho. Eu acho que tem que conversar com o pessoal da família. Acho que é a única coisa, porque a pessoa geralmente não nega quando conversam direito com ela [...] E5

Quando se pensa na problemática da doação de órgãos, particularmente sobre o grande número de recusas por parte das famílias, percebe-se que existem muitos fatores envolvidos, dentre esses o modo como a cultura ocidental lida com a morte nos dias de hoje. De maneira geral, existe um temor muito grande em falar de morte. É natural que conversar sobre o fim da vida gere angústia e preocupações, afinal, falar com uma pessoa querida sobre a sua morte, não é fácil.

A morte é entendida como um processo que decorre do modo como a sociedade ou os grupos sociais atribuem sentido à vida e se relacionam com a finitude. É uma experiência individual, intransmissível, inapelável e solitária que a sociedade contemporânea ocidental procura ocultar, ou enfrentar por meios "heroicos" no sentido de postergá-la.

O pavor da morte acompanha a humanidade em todas as épocas e em diferentes culturas, pelos sentimentos de dor devidos à perda da individualidade, pelo não reconhecimento do corpo morto como pessoa, mas como cadáver ou restos mortais. ${ }^{23,24}$ Logo, falar sobre morte incomoda, mas, quando se trata de doação de órgãos essa conversa é imprescindível.

As representações do corpo e de seus órgãos são plenas de simbolismos. Por exemplo, o coração é representado como sede de sentimentos e sede da alma, o "local onde Deus habita"; os olhos como receptores através dos quais o mundo "penetra" no indivíduo. Desse modo, além das funções fisiológicas de cada órgão, eles têm ainda valores afetivos agregados, e fazem parte de um todo que depende de cada uma dessas partes para a sua completa significação. ${ }^{25}$

Embora a população receba mais informação sobre o assunto através das campanhas, ainda há muito a ser feito no que diz respeito à conscientização, conforme revela o seguinte depoimento:

[...] isso ai devia ser mais esclarecido para população saber mais sobre a utilidade que tem a doação de um órgão [...] E15.

É preciso que as tentativas de convencer as pessoas sejam substituídas pelo reconhecimento do direito da população em receber informações esclarecedoras sobre todos os aspectos envolvidos no processo e seja respeitado seu direito de decisão. ${ }^{1}$ Essa idéia permeou o discurso dos familiares:

[...] se a pessoa achar que deve doar, tudo bem. Se achar que não deve, cada um é cada um [...] E2. 
Não se pode mudar o pensamento e o comportamento sociocultural de uma hora para outra. É preciso que os profissionais de saúde, principalmente aqueles que estão diretamente envolvidos nos processos de captação-doação-transplante de órgãos, mantenham seu pensar e seu agir embasados na ética, tanto em relação à família e à pessoa representada pelo potencial doador, quanto em relação à comunidade onde estão inseridas. ${ }^{26}$

\section{CONCLUSÃO}

Com este estudo foi possível identificar aspectos importantes do comportamento dos familiares frente a uma situação tão delicada: a decisão sobre a doação de órgãos de um ente querido, frente ao diagnóstico de morte encefálica. Além do sofrimento e dos desarranjos causados no seio familiar pela perda repentina, a negativa dessas famílias em consentir a doação de órgãos expressa algumas de suas percepções sobre a vida, a morte e as relações socioculturais referentes a ambas que vão se estabelecendo por meio de suas vivências. A decisão dos familiares é afetada por crenças e emoções ligadas a essa prática contemporânea - morte encefálica e doação de órgãos - sendo necessário considerar as dimensões culturais, científicas e éticas que envolvem a tomada de decisões.

O apego ao corpo e a dificuldade em aceitar sua finitude emergem das falas dos entrevistados, especialmente nesse contexto de morte não esperada. Sentimentos mórbidos acabam surgindo com a interpretação equivocada de que, mesmo com morte encefálica, as intervenções cirúrgicas no corpo do potencial doador provocarão maior sofrimento.
Os familiares são tomados por sentimentos ambíguos, rejeitando a finitude e ao mesmo tempo desejando iniciar, imediatamente, o processo de luto, seguindo os rituais que acompanham a morte em nossa sociedade. Logo, a permanência do falecido por um tempo maior no hospital para retirada de órgãos constitui motivo importante de recusa à doação. Medidas que visem a redução desse tempo de espera e o aprimoramento da infra-estrutura hospitalar para a retirada de órgãos dos doadores, certamente facilitariam a doação.

Foi possível notar a necessidade de refletir e discutir os diversos aspectos que envolvem o tema da doação de órgãos para transplante, sob o ponto de vista da bioética, de maneira ampla e com envolvimento da sociedade, possibilitando maior compreensão sobre todo o processo da doação.

Além disso, os outros motivos das recusas, a saber: falhas na orientação sobre a doação, desconhecimento do desejo do falecido e desconfiança relacionada ao serviço de saúde, trazem informações relevantes a todos os envolvidos nos processos de captação-doação-transplante de órgãos. A identificação desses motivos fornece subsídios para que se efetivem mudanças na busca pelo objetivo maior: a melhoria da qualidade de vida de milhares de pessoas.

Os profissionais que lidam no dia-a-dia com a morte, correm o risco de se tornarem insensíveis à dor e ao sofrimento do outro, portanto é imprescindível relembrar que na situação de alto nível de estresse vivida pela família, o profissional de saúde deve cumprir com seu dever fundamental: acolher e cuidar.

\section{ABSTRACT:}

Purpose: Study aiming to understand the reasons for the refusal to donate organs by relatives of potential donors living in the Mid-Western region of the São Paulo state. Method: Qualitative study performed after data collection by the Organ Procurement Organization (OPO) Division of a reference hospital in the region. Relatives were contacted to participate in a semi-structured interview, and after the subjects in the study were characterized, four guiding questions were presented; their respective answers were recorded to be transcribed later. The Analysis of Content method proposed by Bardin was used to organize the speeches. Results: From 2006 to 2008, 30 (35.3\%) families contacted by OPO have refused to agree with the organ donation. From that universe, 16 family members were interviewed. Data was systematized in three major themes: The experience of being informed on a family member's brain death, decision concerning to the organ donation and aspects that would facilitate the decision to agree with the organ donation. Conclusion: the identification of reasons for the refusal and the suggestions presented has provided subsidies to improve the organ donation for transplantation process.

Keywords: Brain Death; Organ Transplantation; Family; Bioethics.

\section{REFERÊNCIAS:}

1. Faria JG, Branco LM, Duarte O.S.; Miyasaki, M.C.O.S.; Filho, M.A. Doação de órgãos para transplantes: informação e opinião de moradores do interior do Estado de São Paulo. JBT J Bras Transpl. 2007;10:752-5.

2. Dalbem GG, Caregnato RCA. Doação de órgãos e tecidos para transplante: recusa das famílias. Texto Contexto - Enferm. 2010;19:728-35.

3. UNICAMP [homepage na Internet]. Campinas: Universidade Estadual de Campinas; c1994-2008 [acesso em 2008 Nov 30]. HC comemora 15 anos da OPO e anuncia transplantes de pulmão e ósseo para 2009. Disponível em: http://www.unicamp.br/unicamp/divulgacao/2008/09/25/hccomemora-15-anos-da-opo-e-anuncia-transplantes-de-pulmao-e-osseopara-2009-0.
4. Filho MA. Desvendando as causas de não efetivação dos potenciais doadores de órgãos: educar para não punir... quem? JBT J Bras Transpl. 2006;9:461-508.

5. Sadala MLA. A experiência de doar órgãos, na visão de familiares de doadores. J Bras Nefrol. 2001;23:143-51.

6. Solar PS, Ovalle RA, Simian MME, Escobar HJ, Beca IJP. Tres factores que influyen en la actitud de las personas ante la donación de órganos. Rev Chil Cir. 2008;60:262-7.

7. Santos MJ, Massarollo MCKB. Processo de doação de órgãos: percepção de familiares cadáveres. Rev Latino-am Enferm. 2005;13:382-7. 
8. Painter LM, Langlands JM, Walker JI. Donor families experience of organ donation: a New Zealand study. N Z Med J. 1995;108:295-6.

9. Bonnet F, Denis V, Fungencio J.P, Beydon L, Darmon PL, Cohen S. Interviews with families of organ donors: analysis of motivation for acceptance or refusal of donation. Ann Fr Anesth Reanim. 1997;16:492-7.

10. Ministério da Saúde. Coordenação Geral do Sistema Nacional de Transplantes. [homepage na Internet]. [acesso em 2009 Jul 18]. Disponível em: http://portal.saude.gov.br/portal/arquivos/pdf/opo_pmp71111.pdf.

11. Fogueral F. OPO realiza a milésima captação de córnea. Jornal da FMB. Seção 10, Ago 2008.

12. Rech TH, Filho EMR. Entrevista familiar e consentimento. Rev. Bras. Ter. Intensiva. 2007;19:85-9.

13. Bardin L. Análise de conteúdo. São Paulo: Edições 70; 1998.

14. Brandão FRM. A repercussão da morte de um filho na organização e estrutura familiar [monografia]. Salvador: Centro Universitário Jorge Amado; 2010

15. Mendes JA, Lustosa MA, Andrade MCM. Paciente terminal, família e equipe de saúde. Rev SBPH. 2009;12:151-73.

16. Junior AS, Rolim LC, Morrone LC. O preparo do médico e a comunicação com familiares sobre a morte. Rev Assoc Med Brás. 2005;5:11-6.

17. Moreira CV, Ferraz BER. Receptividade da notícia de morte encefálica nos familiares de doadores de órgãos e tecidos para transplante. Enferm Glob. 2009;16:1-8.
18. Moraes EL, Silva LBB, Glezer M, Paixão NCS, Moraes TC. Trauma e doação de órgãos e tecidos para transplante. JBT J Bras Transpl. 2006;9:561-5.

19. Moraes EL, Massarollo MCKB. Recusa de doação de órgãos e tecidos para transplante relatados por familiares de potenciais doadores. Acta Paul Enferm. 2009;22:131- 5.

20. Lima AAF, Silva MJP, Pereira LL. Sofrimento e contradição: o significado da morte e do morrer para enfermeiros que trabalham no processo de doação de órgãos para transplante. Enferm Glob. 2009; 15:1-17.

21. Brasil. Senado Federal. Lei $\mathrm{n}^{\circ}$ 10.211, de 23 de março de 2001. Altera dispositivos da Lei $\mathrm{n}^{\circ}$ 9.434, de 4 de fevereiro de 1997, que "dispõe sobre a remoção de órgãos, tecidos e partes do corpo humano para fins de transplante e tratamento”. Diário Oficial da União. 23 mar. 2001. Seção 1, p. 10.

22. Coelho JCU, Cilião C, Parolin MB, Freitas ACT, Filho OPG, Saad DT. Opinião e conhecimento da população da cidade de Curitiba sobre doação e transplante de órgãos. Rev Assoc Méd Brás. 2007;53:421-5.

23. Roza BA, Garcia VD, Barbosa SF, Mendes KD, Schirmer J. Doação de órgãos e tecidos: relação com o corpo em nossa Sociedade. Acta Paul Enferm. 2010;23:417-22.

24. Bellato R, Carvalho EC. O jogo existencial e a ritualização da morte. Rev. Latino-Am. Enfermagem. 2005;13:99-104

25. Bendassolli PF. Doação de órgãos: meu corpo, minha sociedade. Psicol. Reflex. Crit. 1998;11:71-92.

26. Paulino LAF, Teixeira SLC. Educação Médica. Ética em transplantes. Rev Med Minas Gerais. 2009;19:264-8 